Cadernos de Filosofia Alemã 4, PP. 43-64, 1998

\title{
Imperativo categórico e doutrina do direito*
}

\author{
Daniel Tourinho Peres**
}

Resumo: Este texto visa investigar a relação entre imperativo categórico e uma doutrina do direito que tem nele um pressuposto valorativo para a possibilidade moral da coerção.

Palavras-chave: imperativo categórico - direito - lei moral - lei jurídica - coerção

Não há nada no mundo tão sagrado como o direito dos outros. Bondade é supérflua.

Kant, Vorlesung über Ethik.

Em 1797, Kant inicia a publicação da Metafísica dos Costumes, oferecendo ao público leitor sua primeira parte, os Princípios Metafísicos da Doutrina do Direito, a que se seguem, ainda no mesmo ano, os Princípios Metafisicos da Doutrina da Virtude. Passaram-se mais de dez anos - pois Kant, no Prefácio à Fundamentação da Metafísica dos Costumes, texto de 1785, dá notícia de sua intenção de um dia publicar sua Metafísica dos Costumes (Kant 10, IV , 391) - para que seus leitores tivessem por fim a obra à mão. Em verdade, pode-se ter por certo que o plano de escrever uma tal Metafísica já ocupava Kant desde muito antes. Tanto uma carta de Kant a Herder, datada de 9 de maio de 1767, quanto uma carta de Hamman ao mesmo Herder, esta escrita

\footnotetext{
* Este texto é uma versão do primeiro capítulo da dissertação de mestrado Kant e a fundamentação do direito político, orientada pelo Prof. José Arthur Gianotti e apresentada no Departamento de Filosofia da FFLCH-USP em novembro de 1997.

** Professor assistente do Departamento de Filosofia da FFCH-UFBA e doutorando no Departamento de Filosofia da FFLCH-USP.
} 
em 16 de fevereiro, também de 67, demonstra a esperança de Kant em ter o referido texto concluído ainda nesse mesmo ano (Kaulbach 13, p. 02). Também na "Arquitetônica" da Crítica da Razão Pura, Kant refere-se a uma Metafísica dos Costumes (Kant 10, III, 544), texto que comparece nas duas edições. O motivo do adiamento? Com a descoberta da Crítica, uma nova concepção de objetividade entra em linha de conta na filosofia. E, se isto vale para a filosofia da natureza, cujo objeto não se deixa mais ver como coisa em si, mas como fenômeno, vale também para a filosofia prática, que sofre sua revolução copernicana, ou, se se preferir, revolução rousseauísta, para falar como Beck (Beck 4, p. 130). Pois, um objeto prático vem a ser a ação de um ser cuja vontade é imediatamente determinada pela lei moral, lei da razão pura prática, que encontra no imperativo categórico ${ }^{1}$ sua formulação e do qual podem ser derivados todos os outros imperativos do dever (Kant 10, IV, 421).

É com a Fundamentação que Kant dá início à sua filosofia moral propriamente crítica (Kersting 15, p. 117), que tem seu núcleo no conceito de autonomia. Assim, só tem valor prático-obrigante aquela lei que o sujeito impõe a si mesmo, em virtude de sua natureza racional. O imperativo categórico, ao exigir essa autocoerção, exige ao mesmo tempo que a ação seja feita por dever e não apenas em conformidade com o dever. Daí Kant, partindo do conceito de uma vontade absolutamente boa, analisar regressivamente (Almeida 2, p. 96) as condições que uma tal vontade deve satisfazer para ter seu valor assegurado. Mas, se o imperativo categórico verdadeiramente exige que toda ação se dê aus Pflicht, o que não deixa ver é como operaria em uma Doutrina do Direito, a qual toma como suficiente que uma ação seja realizada em conformidade com o dever, pouco importando se a simples idéia do dever ou um outro móbil qualquer tenha sido a razão a partir da qual se agiu de um determinado modo. Aqui, no direito, tudo o que importa é a simples legalidade de uma ação, não sua moralidade - e, para se obter uma tal legalidade, a coerção parece ser o instrumento mais apropriado. Se aquele que age legalmente o faz por receio de uma sanção, então a lei jurídica teria num imperativo hipotético sua formulação (Bobbio 5, p. 65).

Ocorre, contudo, que o imperativo categórico é o princípio (Grundsatz) supremo da doutrina dos costumes (Kant 10, VI, 226) e não de uma doutrina da virtude, apenas, ou seja, é o princípio supremo tanto da ética quanto do direito; é o princípio do qual será derivado todo princípio prático, seja na forma de lei ética, seja na forma de lei jurídica. A Fundamentação, se desco- 
nhece qualquer distinção entre ética e direito, é porque tem como tarefa principal - senão única - "a investigação e estabelecimento do princípio (Prinzip) supremo da moralidade" (Kant 10, IV, 392), não sendo, de modo algum, necessário tratar - como em uma Metafísica dos Costumes - dos princípios de aplicação do princípio (id., ibid., VI, 216/217) (ver também GoyardFabre 6, p. 48). Ocupando-se em apresentar o fundamento de um discurso racional e portanto válido para todo ser dotado de razão, a Fundamentação não é a metafísica dos costumes propriamente dita (Weil 24, pp. 148-49), esta devendo conter um enraizamento na natureza humana, do qual a filosofia prática, em sua parte fundante, deve fazer abstração. Destarte, a Fundamentação, bem como a Crítica da Razão Prática, faz do imperativo categórico o primeiro momento da constituição da objetividade prática, que Bernard Rousset virá chamar momento da determinação pura (Rousset 22, pp. 504-508). Pois, antes de se julgar acerca da racionalidade de qualquer ação, querer, ou mesmo instituição, é o critério mesmo de racionalidade que deve ser objeto de análise. Este critério não é senão o imperativo categórico, que terá na lei jurídica uma versão especializada (Kersting 15, p. 128). O que se pretende saber, então, é como o imperativo categórico serve de fundamento também para o direito.

\section{Primeira aproximação do conceito de direito, imperativos hipotéticos e categórico}

Assim como a Fundamentação, também a Metafísica dos Costumes distingue entre leis da natureza e leis da liberdade, as últimas designando-se como morais (moralisch) (Kant 10, IV, 387; VI, 214). Mas, a Metafísica dos Costumes introduz mais uma distinção que, ao menos aparentemente, não encontra qualquer correspondente na Fundamentação. Pois, agora, as leis da liberdade, na medida em que se ocupam das "ações puramente exteriores e de sua conformidade à lei (Gesetzmässigkeit), elas são designadas como jurídicas"; as leis éticas, por sua vez, são aquelas que devem, elas mesmas, ser o princípio de determinação da ação. Deste modo, as leis jurídicas definem a legalidade (Legalität) da ação, as éticas, sua moralidade (id., ibid.). Com isso, tem-se uma primeira aproximação do conceito do direito como o conjunto de leis que cuidam de ações puramente exteriores e de sua conformidade à lei. $\mathrm{O}$ direito, porque cuida apenas da relação exterior entre os arbítrios, pode deixar de lado qualquer consideração quanto às intenções dos agentes. 
É justamente do fato de o direito se ocupar com a conformidade de uma ação à lei que o argumento que pretende ver na lei jurídica um imperativo hipotético tira sua maior vantagem ${ }^{2}$. Seu preço, contudo, consiste em ver negado o estatuto de moralmente obrigante a qualquer lei jurídica - como se verá, só o imperativo categórico comporta um modo de constrangimento que, incondicionado, Kant chamará de obrigatoriedade [Verbindlichkeit] e ao qual corresponde uma obrigação [Verpflichtung]. Os imperativos hipotéticos podem ser ou técnicos, ou prudenciais, conforme se refiram a um fim possível ou real, mas, em ambos os casos, o fim é sempre subjetivo. Tomar o imperativo jurídico como imperativo pragmático prudencial - e que estaria se dirigindo para a satisfação de um fim real, a felicidade - equivaleria a incorrer num eudaimonismo jurídico, fazendo da felicidade dos cidadãos que se encontram sob uma ordenação jurídica o objeto mesmo do direito. Sobre este ponto, Kant é, certamente, taxativo. A propósito de um povo que, em nome de sua felicidade, arvorar-se-ia ter um direito de resistência contra o soberano, ou mesmo contra o governo, Kant escreve: [com relação ao direito] "não se trata aqui da felicidade que o sujeito pode esperar de uma instituição ou governo do ser comum... Relativamente à felicidade, nenhum princípio universal válido pode ser dado como lei" (Kant 10, VIII, 298). Quanto ao imperativo jurídico ser um imperativo técnico, isto equivaleria a transformar o direito numa arte, já que Kant, na Primeira Introdução à Crítica do Juízo, corrigindo terminologia empregada na Fundamentação, vem agora chamar os imperativos problemáticos de técnicos, "isto é, imperativos da arte" (idem 12, p. 36) ${ }^{3}$.

O imperativo categórico, Kant o reitera várias vezes, é fórmula da lei moral, lei prática 4 . Essa lei, para que "ela deva ter valor moral, ou seja, como fundamento de uma obrigatoriedade [Verbindlichkeit], faz-se necessário que implique consigo uma absoluta necessidade" (idem 10, IV, 398). Quando Kant, na Fundamentação, apresenta a distinção entre os diversos imperativos - hipotéticos e categórico, os primeiros podendo ser problemáticos ou assertóricos, o último tendo que ser apodítico (id., ibid., IV, 414) -, o que pretende é demonstrar que, ainda que todos exprimam um dever, não se deve atribuir a este termo um mesmo sentido. Pois, se cada imperativo resulta ser uma regra que a razão prática prescreve para um sujeito cuja vontade não se determina necessariamente por ela, ou seja, para uma vontade humana, a determinação da vontade que se deve pôr em conformidade com as leis objetivas vem a ser um constrangimento [Nötigung] (id., ibid., IV, 413). O que importa, então, é ana- 
lisar o gênero de constrangimento que cada imperativo implica, só o imperativo categórico tendo seu constrangimento como um dever moral.

Um imperativo hipotético, seja ele técnico ou pragmático, constrange sempre condicionalmente. Como tal imperativo é uma regra que se dirige para a obtenção de um fim (Kant 10, IV, 414) - sendo este fim contingente, ou seja, podendo ou não ser o fim da vontade de um sujeito particular -, o ver-se constrangido a seguir a regra dependeria da eleição prévia, pelo sujeito, do fim para o qual a regra apresenta os meios de obtenção (id., ibid., IV, 420) daí sua condicionalidade. Se ainda se podem considerar imperativos hipotéticos como leis objetivas, sua objetividade é de outra ordem que não prática. Porque "enunciam imediatamente a possibilidade de um objeto por nosso arbítrio, pertencem sempre ao conhecimento da natureza e à parte teórica da filosofia" (idem 12,p. 35), e só são objetivos na medida em que "constituem a parte prática da filosofia da natureza" (id., ibid., p. 33).

O imperativo categórico, por sua vez, expressão da lei moral, não pode conhecer qualquer condição; o princípio objetivo, do qual ele é a representação (idem 10, IV, 413), comanda incondicionalmente. E tudo o que ele comanda, uma vez que se deve fazer abstração de qualquer fim - pois o valor moral de uma ação, ação por dever, extrai-se não do fim a ser por ela atingido, mas da máxima a partir da qual ela é decidida (id., ibid., IV, 399) -, é a necessidade de a máxima ser conforme a lei moral, a qual não conhece qualquer condição. O imperativo categórico, único, é então: "Age apenas segundo uma máxima tal que possas ao mesmo tempo querer que ela se torne uma lei universal" (id., ibid., IV, 420-1). O que se tem com ele é a representação, não de uma ação que se dirige para a obtenção de um fim, mas de uma "ação por si mesma, e sem vínculo com nenhum outro fim, como objetivamente necessária" (id., ibid., IV, 414).

Todo o esforço de Kant, ao menos nas duas primeiras seções da Fundamentação, consta de: em primeiro lugar, mostrar onde se encontra o valor moral de uma ação, ou seja, que uma ação deve dar-se por dever, e não apenas em conformidade com o dever; em segundo, que agir por dever é agir tendo como princípio de determinação da vontade a lei moral, apenas; em terceiro, se é que o conceito de dever tem sentido e não é apenas mais uma quimera, é necessário que haja um princípio que, sendo puramente formal - porque abstrai de qualquer fim material -, ainda assim seja princípio de determinação da vontade de um ser racional, princípio que se vê formulado no imperativo categórico; por último, que este princípio e toda obrigatoriedade dele decorrente 
têm na razão pura prática sua origem, de modo que a lei moral não é senão expressão da autonomia da vontade, que, como se pode ler na segunda Críti$c a$, é "princípio único de todas as leis morais e dos deveres a elas conformes" (Kant 10, V, 33).

Mas, o imperativo categórico obriga a agir por dever? ou melhor, não comporta ele, para a ação, nenhuma outra determinação que não a moralidade? Se o imperativo, em última instância, é o princípio do qual todos outros imperativos de deveres são derivados (id., ibid., IV, 421), deve-se entender tais deveres como éticos em sentido estrito, i. e., deveres de virtude, para os quais nenhuma legislação externa é possível? Se a resposta for afirmativa, de modo a ver o imperativo categórico como ocupado apenas em determinar a intenção do agente tal como esta se expressa em sua máxima, princípio subjetivo, então, imperativo categórico e lei jurídica devem estar separados como água e óleo.

\section{Imperativo categórico, princípio judicatório}

O imperativo categórico, segundo o texto da Doutrina da Virtude, não passa de um princípio negativo a avaliar se as máximas qualificam-se para uma legislação universal, com a seguinte precisão, porém: na ética, essa lei (o imperativo categórico) é pensada como lei da vontade do próprio agente, e não como lei de uma vontade em geral, o que daria origem a um dever de direito (id., ibid., VI, 388-9). Afirmar, contudo, que o imperativo categórico é um princípio negativo não significa tomá-lo como critério da legalidade - da conformidade à lei - das ações, para, a partir daí, o termos como fundamento também do direito. $\mathrm{O}$ imperativo categórico, como princípio de universalização, considera a universabilidade por ele exigida como critério de máximas moralmente proibidas e com isso, indiretamente, como critério de máximas moralmente permitidas, mas não - como freqüientemente admitido - como critério de máximas a que se está moralmente obrigado (sittlich gebotener Maximen) (Höffe 9, p. 103).

Quando Kant, na Metafísica dos Costumes, apresenta a definição de imperativo, o faz em três momentos: "o imperativo é uma regra prática, através da qual uma ação em si mesma contingente é tornada necessária". Nesse primeiro momento, imperativo distingue-se de lei prática, uma vez que a esta pouco importa que a ação seja em si contingente, ou seja internamente necessária para um sujeito. "Então, escreve Kant, o imperativo é uma regra cuja 
representação torna necessária a ação subjetivamente contingente; por conseqüência, representa um tal sujeito como devendo ser constrangido [genötigt] (necessitado [nezecitiert]) a se pôr em acordo com esta regra" (Kant 10, VI, 222). Mas é a terceira definição a que se mostra mais importante: "O imperativo categórico (incondicionado) é o que pensa e torna necessária a ação, não de maneira mediata, através da representação de um fim que poderia ser atingido pela ação, mas através da simples representação desta ação mesma (de sua forma), então de maneira imediata, como objetivamente necessária".

O imperativo pensa e torna necessária a ação. Além disso, conforme a segunda definição, representa o sujeito como devendo ser constrangido. Mas, ele determina o modo desse constrangimento? Se Kersting, com razão, distingue na lei jurídica, ou melhor, no direito, entre praktische necessitas e praktische necessitatio, não há também que se afirmar que o imperativo categórico não possui qualquer praktische necessitatio? Kersting cita a Vorlesung über Ethik (idem 11) ${ }^{5}$. Tomando terminologia deste texto, o imperativo categórico é o princípio judicatório de toda obrigatoriedade (Verbindlichkeit) moral e deve ser distinguido do princípio executório (id., ibid., p. 46). Aqui não se tratará de saber se Kant, afinal, encontrou ou não a pedra filosofal, ou seja, como ao juízo (Verstandesurteil) é conferida uma força capaz de transformálo em móbil (id., ibid., p. 54). O que importa é saber se, no imperativo categórico, "fundamento de conhecimento e fundamento de execução são idênticos"6, ou se é possível distinguir aí entre dois momentos da constituição do objeto prático. Simplesmente, na constituição de uma objetividade jurídica, essa identidade, diferentemente da ética, não se faz necessária.

Por princípio judicatório, Kant entende a norma que justamente irá determinar toda a objetividade prática: "Fundamentos da judicação são objetivos, mas fundamentos da execução podem ser também subjetivos (...) Então a questão da moralidade de forma alguma se refere a fundamentos subjetivos, mas só pode ser resolvida segundo os fundamentos objetivos" (id., ibid., p. 34).

É como princípio judicatório, como fundamento de conhecimento (Erkenntnisgrund), que "o imperativo categórico, enquanto princípio do moralmente necessário bem como do moralmente possível, é ao mesmo tempo o princípio da ação coercitiva moralmente possível, assim como das ações moralmente necessárias legitimamente coercíveis" (Kersting 15, p. 128). Assim, o imperativo categórico não é princípio apenas de uma obrigação ética que, além da lei, do imperativo categórico mesmo, demanda ainda o conceito de um fim, que seria ao mesmo tempo um dever. Isso sim, é princípio de toda 
obrigação, seja ela obrigação por dever, seja obrigação coercitiva. A propósito dos conceitos que são comuns às duas partes da metafísica dos costumes, Kant escreve: "Obrigatoriedade é a necessidade de uma ação sob um imperativo categórico da razão" (Kant 10, VI, 222) 7 .

Se o imperativo categórico, assim tomado, ainda obriga a algo, não se deve crer que ele obriga a uma ação, como afirma Bobbio: "Você deve executar a ação A". Muito mais que uma ação, aquilo a que ele obriga é a adoção de um ponto de vista ${ }^{8}$, a partir do qual o sujeito deve-se considerar como estabelecendo, através de suas máximas, uma legislação universal (id., ibid., IV, 433). É a partir desse ponto de vista, ponto de vista da razão, que o homem pode julgar que, se através do conceito de dever ele se encontra ligado a leis, ele não está submetido senão à sua própria legislação universal (id., ibid., IV, 432). O princípio a partir do qual o homem deve julgar todas as suas ações é o princípio da autonomia da vontade. E todas as ações que se mostram como caso da regra são necessárias.

\section{Das duas partes da legislação da razão prática}

O imperativo é formulação da lei moral por excelência, da qual toda legislação da razão pura prática será derivada. Costuma-se afirmar que a posição de Kant diante do jusnaturalismo consiste numa recusa, por parte de Kant, de fundar o direito na lei moral. A esse respeito, escreve Goyard- Fabre: "Sobre esse ponto, Kant se opõe a Hufeland, que na sua obra de 1790, Lehrsätze des Naturrecht, encontrava na lei moral o fundamento do direito" (GoyardFabre 7,p. 27). Mas, há que se duvidar desta afirmação, a menos que se precise o que se entende por lei moral. Pois Kant, em sua resenha da Investigação acerca do princípio do direito natural, também de Hufeland e publicado em 1785 , irá colocar o problema nos seguintes termos: "O próprio do sistema de nosso autor consiste em que ele põe o fundamento de todo direito natural e de toda faculdade (Befugnis) em uma obrigatoriedade natural prévia, e em que ao homem é facultado (befugt) coagir o outro porque é a isto obrigado" (Kant 10, VIII, 128).

O que afasta Kant de Hufeland é que este trouxe, para dentro de uma fundamentação do direito, um problema concernente à ética. Pois, a faculdade de coagir, jurídica, não é derivada de um dever ético. Não é porque alguém é obrigado, a partir de uma legislação ética, a promover sua própria perfeição, 
ou a agir por dever, para ficar nos termos do próprio Kant, que a ele se vê concedida a faculdade de obrigar os outros a fazerem o mesmo. $\mathrm{O}$ que se pode, então, esperar de Goyard-Fabre é que não reduza a lei moral à lei ética, até porque quando Kant for tratar das leis que obrigam e que proíbem, leis morais, ver-se-á que se trata de leis éticas e jurídicas. Como não o faz, não pode deixar de afirmar que se "a legislação jurídica, para o sujeito do direito, significa assim heteronomia, é porque a ordem jurídica se serve, em sua obrigatoriedade mesma, da coerção [Zwang]" (Goyard-Fabre 7, p. 28).

Mas, que se deixe o problema de uma fundamentação racional da coerção para mais adiante. De resto, diga-se apenas que a coerção é fundamentada indiretamente e através da faculdade de coagir, esta sendo, em seu fundamento, independente de qualquer legislação ética. Nesse ponto, é chegado o momento de apresentar sistematicamente essas duas legislações, ética e jurídica, quanto a sua distinção. O conceito de que se deve partir para obter a divisão do "reto (fás) ou não reto (nefas)" é o conceito de "ato do arbítrio em geral" (Kant 10, VI, 219). Por ato, Kant entende uma ação na medida em que esta se encontra sob leis de obrigatoriedade (Verbindlichkeit). Como essas leis são fornecidas pela razão pura prática, o sujeito se considera do ponto de vista da liberdade do seu arbítrio (id., ibid., VI, 223). Mas, as ações podem ser exteriores ou interiores. Uma ação exterior não parece trazer maiores problemas: é uma ação que se inscreve no mundo e que vai ao encontro de outros homens, também agentes, acabando por circunscrever um mundo intersubjetivo, onde as diferentes subjetividades se põem umas diante das outras. Uma ação interior, por sua vez, não circunscreve nenhum campo de intersubjetividade, mas é tão-somente, como escreve Kersting, intra-subjetiva (Kersting 15, p. 183). Essa ação interior é ato de liberdade, fundamento subjetivo da adoção de máximas (Kant 10, VI, 21) e através do qual o arbítrio elege os fins a que irá dirigir sua ação.

Agora que se dividiram os atos do arbítrio em ações exteriores e interiores, todas submetidas à legislação da razão, faz-se necessário que a legislação da razão tome, também ela, uma dupla via, conforme legisle com relação a ações exteriores ou interiores: "As leis da liberdade, à diferença das leis da natureza, chamam-se morais (moralisch). Na medida em que elas se dirigem apenas às ações meramente exteriores e a sua conformidade à lei, chamam-se jurídicas; mas se exigem também que elas (as leis) mesmas devem ser o princípio de determinação (Bestimmungsgrund) das ações, então, são éticas [ethisch]" (id., ibid., VI, 214). 
Há que se reconhecer que o direito não se opõe à moral. Pelo contrário, "moral, em sentido amplo, compreende a doutrina dos costumes", da qual fazem parte ética e direito. Mais uma vez, como afirma Ricardo Terra, não se "podem tomar como correlatos os pares moral/direito e moralidade/legalidade" (Terra 23, p. 77). Mas, se o direito, em sua fundamentação, irá se mostrar independente da ética, não parece haver razão para se ver uma oposição entre essas duas legislações - até porque cada uma delas estará determinando objetos distintos. Melhor seria falar em coordenação, dando a cada uma aquilo que lhe é de direito (quid iuris): à legislação ética, que sua lei mesma seja princípio de determinação, de modo a que a ação que se põe em concordância com a sua lei possua moralidade; à jurídica, porque pouco lhe importa o princípio de determinação, que legisle acerca das ações no que essas têm de exterior, garantindo-lhes a legalidade. Daí se vê que, do ponto de vista de uma legislação jurídica, a legalidade é o máximo de determinação que uma ação pode receber. De resto, é importante notar que Legalität é um predicado da ação e teria, ainda sob esse ponto de vista, o seu oposto no conceito de ausência de lei, senão de oposição à lei. Só de um ponto de vista de uma legislação ética, uma ação que é apenas conforme à lei apresenta um déficit de determinação: "Legalidade designa aqui uma forma deficiente da constituição moral interna do sujeito da ação" (Kersting 15, p. 178).

A legislação jurídica legisla quanto às ações exteriores e não quanto às intenções do agente. Essa distinção, no âmbito da legislação da razão prática, implica mais uma divisão, desta vez dentro de cada uma das legislações: "Toda legislação (prescreva ela ações interiores ou exteriores, e estas seja a priori pela simples razão, seja através do arbítrio de um outro) comporta duas partes: primeiro, uma lei que representa objetivamente a ação que deve acontecer como necessária, ou seja, que faz da ação um dever; em segundo, um móbil que liga subjetivamente à representação da lei o princípio de determinação do arbítrio a essa ação; por conseqüência, é nesta segunda parte que a lei faz do dever um móbil" (Kant 10, VI, 218).

Toda legislação é composta de duas partes. Isso significa que, em toda legislação, princípio judicatório e princípio executório devem ser considerados como dois momentos distintos da constituição do objeto prático. O que irá definir uma ação como objetivamente necessária, isto é, como dever, não é o modo a partir do qual se levará a termo a obrigatoriedade (Verbindlichkeit) por ele implicada, mas sim a própria lei. Kant irá afirmar, logo em seguida, que nessa primeira parte tudo o que se tem é um "puro conhecimento teórico 
da determinação possível do arbítrio, ou seja, regras práticas” e que só em sua segunda parte se irão ligar, no sujeito, obrigatoriedade com relação a uma ação e um princípio de determinação do arbítrio.

É nessa segunda parte que as legislações ética e jurídica se diferenciam, e não no âmbito dos deveres éticos ou jurídicos. Um dever, por simplesmente ser dever, já se encontra sob a legislação ética. Mesmo um dever jurídico é indiretamente um dever ético (Kant 10, VI, 220) - o pagar uma dívida contraída é um dever jurídico, mas, também, ético. É então quanto a seu modo execução que cada uma das legislações irá se diferenciar (Kersting 15, p. 180). Pois, enquanto a legislação ética, que se reporta a ações interiores, ou melhor, ao uso da liberdade interior, tem na idéia de dever o móbil de sua ação, a legislação jurídica, dizendo respeito apenas ao uso exterior da liberdade, pode aceitar um outro móbil que não a idéia de dever, móbil este que terá na coerção (Zwang) o seu melhor representante (Kant 10, VI, 219). Mas, há que se acreditar que a coerção legal é o critério do direito, e que a legislação jurídica serve-se, em sua obrigatoriedade (Verbindlichkeit) mesma, da coerção?

Esse é, por excelência, o problema da filosofia do direito de Kant: a possibilidade moral de uma determinação externa do arbítrio, ou seja, a possibilidade moral de uma Befugnis zu zwingen. Na Vorlesung podemos ler: "a coerção não gera obrigatoriedade" (idem 11, p. 43), fórmula que se aproxima muito de Rousseau, quando afirma, no Contrato Social, que a força não gera direito: "convenhamos, pois, que a força não faz o direito e que só se é obrigado a obedecer a poderes legítimos" (Rousseau 21, p. 26). Que todos devem pagar sua dívida, esta é uma proposição afirmando a necessidade de uma ação, de um dever jurídico. Mas, o que torna essa ação um dever jurídico não é o fato de seu não-cumprimento estar previsto num código penal qualquer, nãocumprimento que implicaria em uma pena. Segundo o imperativo categórico, as ações são lícitas ou ilícitas, ou seja, moralmente possíveis ou impossíveis, e algumas são ainda necessárias (Kant 10, VI, 221). O imperativo que obriga aquele que contrai uma dívida a pagá-la, determina como lícita a ação de quem cobra por este pagamento - Hufeland fazia dessa ação uma ação necessária, já que a faculdade de cobrar a dívida era a contrapartida de se ver obrigado a uma tal ação - e como necessária a ação de pagar as dívidas. Kersting, com efeito, afirma que as duas legislações devem diferenciar-se como externa possível - jurídica - e interna necessária - ética (Kersting 15, p. 181). Mas também observa Kersting, o caráter de obrigatoriedade (Verbindlichkeit) de um dever jurídico já está definido desde a primeira parte da legislação, aquela 
em que justamente se definiriam quais ações são deveres. Se se tem uma obrigatoriedade em geral tal como enunciada pelo imperativo categórico e, além dessa, mas dela derivada, uma obrigação ética e jurídica, as obrigações se distinguem pelo modo através do qual serão levadas a termo, pela Verpflichtungsart (Kant 10, VI, 220).

\section{O direito e a coerção moralmente possível}

Kant irá definir o conceito moral de direito, ou seja, o direito na medida em que a ele se vincula uma obrigatoriedade (Verbindlichkeit), em três momentos (id., ibid., VI, 230). No primeiro momento, tem-se que o direito trata apenas da relação exterior entre pessoas, na medida em que essas ações como fakta têm influência umas sobre as outras. Então, o direito é uma relação entre pessoas, i. e., entre os diferentes agentes na medida em que suas ações lhes podem ser imputadas, e isto porque a personalidade moral é "a liberdade de um ser racional submetida a leis morais" (id., ibid., VI, 223). Assim, o direito é uma relação entre pessoas livres e que se sabem submetidas às leis morais, leis a partir das quais o homem revela sua pretensão à liberdade e que se inscrevem como dominação de sua natureza sensível por parte da razão. Um homem que se deixe determinar por móbiles patológicos, que age deliberadamente contra o dever, ainda assim não pode fazer calar a lei moral comofaktum da razão: "a pessoa, enquanto pertencente ao mundo sensível, está sujeita à sua própria personalidade na medida em que ela pertence ao mundo inteligível" (id., ibid., V, 87). Em segundo lugar, trata-se de uma relação entre duas pessoas que efetivamente agem, ou seja, de uma relação entre arbítrios, de pessoas que desejam um certo objeto e são conscientes da sua capacidade para produzi-lo ou alcançá-lo. Por fim, esta relação, a relação jurídica entre os diversos arbítrios, não será construída a partir do objeto, da matéria dos diversos arbítrios: a ela interessa apenas "a forma da relação entre estes arbítrios considerados livres"9 e se nessa relação a liberdade de um se deixa unir com a liberdade do outro segundo uma lei universal (id., ibid., VI, 230). Então, porque cuida apenas da relação exterior e formal entre arbítrios livres, a lei universal do direito é a seguinte: "Age exteriormente de modo que o livre uso do teu arbítrio possa coexistir com a liberdade de todos segundo uma lei universal" (id., ibid., VI, 321). 
O direito não pressupõe a moralidade das ações, ou seja, na medida em que ele se põe como o conjunto das condições a partir das quais os diversos arbítrios podem ser unificados segundo uma lei universal, não precisa esperar, para uma tal união, que os diversos agentes ajam apenas tendo como princípio determinante de suas ações uma intenção moralmente boa, que ajam todos por dever e que sejam todos virtuosos ${ }^{10}$. Tudo a que o direito obriga é que o uso da liberdade por parte de um arbítrio, no que este comporta de exterior, não se ponha como obstáculo ao uso da liberdade de um outro arbítrio segundo leis universais. Desse modo, "é justa toda ação que pode ou cuja máxima pode deixar coexistir a liberdade do arbítrio de cada um com a liberdade de todos segundo uma lei universal". Pode-se mesmo desejar atentar contra a liberdade do outro; o que não se pode, segundo o direito, é passar do desejo à ação (Kant 10, VI, 231).

Que o direito não se ocupa das intenções significa que ele não pode exigir que o sujeito tome o princípio do direito como máxima. Sua lei é lei de uma vontade em geral, que pode ser outra vontade, que não a do próprio agente (id., ibid., VI, 389). Fazer da lei jurídica o princípio de determinação da vontade do próprio agente é transformar um dever jurídico em ético, dever de virtude, alternativa que Kant recusa. Como o direito trata de impedir um certo uso da liberdade que se põe como obstáculo à liberdade segundo leis universais, é necessário encontrar um meio de barrar tal obstáculo, mas um meio que não seja ele mesmo um dever. Tal meio Kant encontrará na coerção, ou melhor, na faculdade de coagir. Como uma ação injusta é um obstáculo à liberdade segundo leis universais, aquilo que se põe como impedição ao obstáculo está em consonância com esta liberdade mesma. Daí duas conseqüências: em primeiro lugar, a coerção se põe como garantia de um uso da liberdade segundo leis universais, e não de qualquer liberdade - a liberdade segundo leis universais é o único direito originário, e a faculdade que se põe como sua garantia, direito subjetivo; em segundo, que a coerção não é de modo algum arbitrária: "exerce a coerção, mas segundo leis" (Refl. 6767). Pois, se a lei universal do direito - "age exteriormente de tal modo que o livre uso de seu arbítrio possa coexistir com a liberdade de cada um segundo uma lei universal" - não exige que se faça dela máxima, i. e., que se a tome como um dever de limitar a liberdade a essas condições, a razão já havia limitado este uso da liberdade: "a razão diz apenas que, em sua idéia, a liberdade é limitada a estas condições". Como a liberdade é objetivamente limitada, no caso de subjetivamente esta limitação não se vir cumprida, pode se ser limitado a essas condi- 
ções pelo arbítrio de um outro. Assim, a relação intra-subjetiva se converte em uma relação intersubjetiva, e "cada hetero-obrigação é sempre uma autoobrigação possível” (Kersting 15, p. 198).

Que a liberdade seja limitada em idéia significa que ela foi assim limitada $^{11}$ pelo imperativo categórico. Como este imperativo é uma lei da razão mesma, então liberdade tem o sentido de autonomia. Quando se considera o problema da limitação no plano jurídico, é possível falar em autonomia jurídica. Para tanto, é necessário, em primeiro lugar, considerar que a lei jurídica, a qual se põe como limitação do uso da liberdade, não é uma lei positiva, ou melhor, não é lei positiva, apenas. Em segundo, se a lei jurídica se vê acrescida de coerção, é necessário ter claro que a coerção deve se exercer dentro de certas condições, as quais são justamente postas pelo direito em seus princí$\operatorname{pios}^{12}$. Se direito é o conjunto das leis externas (leis externas são aquelas para as quais uma legislação externa é possível), estas podem ser tais que as obrigações que elas impõem são a priori reconhecidas pela razão, e isto mesmo sem legislação positiva: "De uma maneira geral, as leis obrigantes, para as quais uma legislação externa é possível, chamam-se leis externas. Dentre estas, aquelas cuja obrigatoriedade (Verbindlichkeit), mesmo sem legislação externa, pode ser reconhecida a priori pela razão são, não obstante externas, naturais" (Kant 10, VI, 224). Essa legislação externa que pode ou não existir, nada implicando quanto à obrigatoriedade de certas leis externas, é uma legislação positiva, a qual deve ser precedida por uma lei natural, onde se irá encontrar o fundamento da autoridade do legislador ${ }^{13}$. Se uma lei jurídica vem determinar a legalidade jurídica de uma ação, é necessário, contudo, não reduzi-la à lei e legalidade positivas. Com efeito, na reflexão 7062, Kant afirma que a legalidade pode ser natural ou civil, e o que definiria, assim, a legalidade de uma ação seria não tanto o fato de esta se encontrar subordinada a uma legislação jurídica positiva, mas sim a aptidão da ação a ser objeto de uma legislação externa moralmente possível, isto é, segundo o direito natural. Com isso, o direito natural, Naturrecht, ou direito racional, põe-se como a instância transcendental através da qual se vê estabelecida a objetividade jurídica, de modo que a legislação externa é não somente possível, mas moralmente possível. Mais ainda, uma Rechtslehre não é senão o "conjunto das leis para as quais uma legislação externa é possível" (id., ibid., VI, 229).

Quando Kant se recusa a dividir o direito estrito em duas partes, a saber, a obrigatoriedade segundo a lei e a faculdade de obrigar o outro através de seu arbítrio, o que ele pretende é que não se veja nessa obrigatoriedade um móbil, 
o que, contudo, não representa uma redução do direito à coerção, pois o que Kant afirma é que "o direito e a faculdade de coagir significam o mesmo" (Kant 10, VI, 232, grifo nosso). Mas essa faculdade de coagir põe-se como a "possibilidade de uma coerção exterior capaz de coexistir com a liberdade de todo outro segundo leis universais". Mais ainda, faculdade de coagir e o conceito de direito só podem ser desenvolvidos a partir da liberdade, cujo conhecimento só é possível através do imperativo moral (id., ibid., VI, 239). Desse modo, Kant pode escrever, no Anúncio da conclusão próxima de um tratado de paz perpétua em filosofia, que o imperativo categórico é a única pedra de toque com relação a toda faculdade (id., ibid., VIII, 420), e, por conseqüência, da faculdade de coagir.

A essa faculdade, na medida em que ela significa uma ação, ou melhor, um ato, corresponde uma máxima como forma da ação, que pode ser objeto do imperativo categórico, se este é tomado em formulação que consta dos Trabalhos prévios à introdução à doutrina do direito: age segundo a máxima da concordância da tua liberdade com a liberdade de cada outro segundo uma lei universal, deixando indeterminado qual fim tem o homem (id., ibid., XXIII, 257) ${ }^{14}$.

Mas, ao se fazer dessa faculdade objeto do imperativo categórico como princípio de universalização, não se pode ver nela uma obrigação que seria ética estrito senso; não se deve esperar que o agente faça dela o princípio de determinação de sua ação. O que se tem é, isso sim, uma ação permitida e que se põe como impedição a ações contrárias a deveres, ao menos a deveres exteriores. Essa impedição, a coerção, na medida em que se põe como obstáculo a um certo uso da liberdade e responde a uma exigência da razão, é, como afirma Kaulbach, em seu fundamento, "fenômeno da liberdade" (Kaulbach 14,p. 51). Certo, não se pode afirmar que a coerção, fruto dessa faculdade, significa tout court autonomia da vontade. Contudo, também, não há razão para tomála como heteronomia ${ }^{15}$. Pois uma ação permitida, se não é autônoma, é, contudo, compatível com a autonomia (Kant 10, VI, 439), sendo ainda a vontade, ou razão prática, que determina, através do imperativo categórico, o arbítrio, ou melhor, sua ação e sua máxima como permitidas; mais ainda quando a ação, a Befugnis zu zwingen dirige-se contra a heteronomia da vontade, a qual se revela em ações que não se deixam coexistir com a liberdade de todo outro segundo uma lei universal.

Isto posto, o imperativo categórico - ratio cognoscendi da liberdade resta sempre como a pressuposição valorativa do direito, e mesmo a coerção 
deve ser a ele submetida ${ }^{16}$. Agora, o direito não legisla para as máximas, mas sim para as ações. Porém, na medida em que as máximas podem ser expressão de um determinado conteúdo material, ou ser expressão formal de uma certa maneira de agir ${ }^{17}$, o direito não determina qual o modo justo de agir para atingir um fim sobre o qual ele não tem a menor jurisdição? Se o direito não determina a máxima materialmente, ou seja, não faz da conformidade de uma máxima à lei o objeto mesmo da máxima, determina-a, contudo, formalmente, enquanto modo e maneira de se conduzir. Essa condição formal da liberdade externa é o acordo da liberdade consigo mesma, quando a máxima é erigida em lei universal (Kant 10, VI, 380). A lei jurídica, assim como o imperativo categórico, é sempre formal. Se a legislação jurídica não obriga a agir por dever, obriga a que as ações se dêem em conformidade com a lei da razão pura prática. Assim como na Fundamentação, na segunda Crítica e na Doutrina da Virtude a conformidade à lei não significa conformidade a uma lei positiva, do mesmo modo a legalidade jurídica não pode ser reduzida a essa. Se o direito é fundado em princípios a priori, a legalidade, determinação que a lei jurídica impõe às ações exteriores, ou a suas máximas, não significa que se está a observar uma lei positiva, apenas. Não é da positividade de uma legislação e da coerção a ela associada que a ação obtém sua determinação prática.

\footnotetext{
Abstract: The text's goal is to investigate the relationship between categorical imperative and a doctrine of right which has in it a valorative pressuposition concerning the moral possibility of juridical coercion.

Key-words: categorical imperative - right - moral law - juridical law - coertion
} 


\section{Notas}

1. Este texto não analisará a dedução do imperativo categórico, bem como dos demais. Conceda-se, apenas, que a lei moral, faktum da razão, tem no imperativo categórico sua formulação e é ratio cognoscendi da liberdade, que, por sua vez, é ratio essendi da lei moral. Tal imperativo, por ser um princípio da razão, acabará por afirmar a autonomia da vontade como "o único princípio de todas as leis morais e deveres a elas conformes" (Kant 10, V,33). É através do conceito de autonomia que será revelada "a capacidade da razão pura de ser por ela mesma prática", o que só é possível "mediante a submissão da máxima de cada ação à condição de sua aptitude [Tauglichkeit] como lei universal” (id., ibid., VI, 214). Mais ainda, é esse imperativo - que revela a pretensão da razão a determinar a vontade imediatamente, pretensão à liberdade - que torna possível ao homem considerar-se, de modo legítimo, como estabelecendo, através de suas ações, um mundo que "escapa" da causalidade natural e que irá se pôr como mundo de liberdade bem-ordenada (Refl. 7202), no qual é possível a unificação dos fins de todos (id., ibid., VIII, 386). Sobre as deduções do imperativo categórico, remete-se a Allison, H. Kant's theory of freedom, Cambridge, Cambridge University Press, 1991, em especial a terceira parte (Allison 1). Pode-se consultar também Beck, L. W. A commentary on Kant's "Critique of Practical Reason”, Chicago, Chicago University Press, 1984, p. 164-76 (Beck 3).

2. Também a propósito da distinção entre legalidade e moralidade, Kant escreve: “A simples concordância ou não concordância de uma ação com a lei, sem consideração do móbil da ação, chama-se legalidade [Legalität] (conformidade à lei [Gesetzmässigkeit]); contudo, aquela na qual a idéia do dever a partir da lei é ao mesmo tempo o móbil da ação é a moralidade [Moralität] (ética [Sittlichkeit] da ação" (Kant 10, VI, 219). Bobbio vê aí, na distinção entre moralidade e legalidade, a primeira distinção entre ética e direito para Kant (Bobbio 5). Porque, então, em uma ação conforme à lei, ou legal, toma-se sempre o objeto como o fundamento de determinação da vontade, e quando se procede assim o imperativo é sempre condicionado, o imperativo jurídico só pode ser hipotético. Contudo, não se deve ver a distinção entre legalidade e moralidade como sendo a mesma que se encontrará entre ética e direito, pois a legalidade pode ser tanto ética quanto jurídica (Refl. 6764). Em uma outra reflexão (Refl. 6767), Kant irá definir a moralidade objetiva como a liberdade submetida a leis. Quando as leis forem internas, a liberdade que a elas se submete será ética; sendo as leis externas, a liberdade é jurídica. Essa submissão, em ambos os casos, é obrigação. Em verdade, quando Kant, na Fundamentação, afirma que aquele que age apenas em conformidade com a lei o faz a partir de um imperativo hipotético - o que irá significar heteronomia -, o que ele entende por isso é que o agente não satisfaz, no princípio de determinação de sua ação, a exigência de uma legislação ética, a saber, fazer da conformidade à lei - tal como representada pelo imperativo - princípio [Prinzip]. Mas essa é uma questão de liberdade interna: fazer da lei moral tal como expessa no imperativo categórico princípio de determinação do querer. 
3. Que, para Kant, a política seja uma arte, é ponto pacífico. Mas, a política não é uma arte, apenas. É, isto sim, uma arte difícil, tensa, e que deve "lidar com com o mecanismo da natureza, com a realidade das instituições e fraquezas humanas" (Terra, 23, p. 172), de modo que as instituições mesmas sejam postas em conformidade com a idéia de direito, tal como apresenta-se em teoria. Se, para tal arte, é imprescindível uma faculdade de julgar aguçada pela experiência, a política não pode se reduzir em lidar com os mecanismos das paixões dos homens, de modo a pô-los em ordem. A política não pode ser, de modo algum, apenas uma física do social e que tem como resultado uma síntese jurídica, que viria a ser, em última instância, uma síntese mecânica externa entre os arbítrios (Essa é a posição de Solari, Studi Storici di Filosofia del Diritto, Turim, Giappichelli, 1949, p. 214. Apud Terra 23, p. 83.) O poder político, ou melhor, o direito político, porque tem realidade prática objetiva, de modo a ter seu conceito força obrigante [verbindende Kraft], funda-se em princípios a priori, "pois, escreve Kant, o que é o direito, a experiência não pode ensinar" (Kant 10, VIII, 306). Com isso, tem-se que política e direito não são idênticos, uma vez que a política é a doutrina do direito em exercício [ausübende Rechtslehre] (id., ibid., VIII, 377). E se há, ou pode haver, subjetivamente, um conflito entre política e moral, entendendo esta não somente como ética mas também como direito, a solução para um tal conflito só pode encontrar-se em um princípio formal, nunca em um princípio material: "age de tal modo que possas querer que a tua máxima deva tornar-se uma lei universal (seja qual for o fim que o arbítrio queira)" (id., ibid.). Assim, o desacordo entre política e moral - que Kant revelará ser aparente - não é um problema de arte (problemum tecnicum), mas é um problema moral (problema morale) e que concerne, justamente, aos princípios do direito, que possuem uma necessidade incondicionada. Para o acordo entre moral e política recorre-se, pois, a certa formulação do imperativo categórico.

4. Kant escreve, na Fundamentação: "Só o imperativo categórico se exprime como lei prática, enquanto os outros imperativos em conjunto podem bem ser chamados de princípios da vontade, mas não de leis" (Kant 10, IV, 420)

5. Não há dúvida que a Vorlesung deve ser utilizada com cuidado, uma vez que se trata de um texto composto a partir de cadernos de notas, que não são do próprio Kant, mas de ouvintes de seus cursos. Como já observava Menzer na Introdução da sua edição de 1924, "todo docente sabe como é digno de nota a freqüente alteração dos seus pensamentos, quando transcritos pelos seus ouvintes". (Kant 11, p. 281). Além disso, como atestam várias passagens, não se deve crer que Kant já tenha se afastado, quando dessas lições, completamente de uma teoria do sentimento moral. Uma discussão sobre esse ponto acabaria por afastar este texto do seu objetivo, de modo que aqui se fará economia de tal discussão. Quanto ao valor da Vorlesung, ver a "Introdução" de Menzer, que consta como Apêndice da edição aqui utilizada (id., ibid.).

6. Essa é a posição de Kersting (Kersting 15). Bernd Ludwig afirma que é por conta da falsa premissa de que lei ética e imperativo são sinôminos que Kersting afirma que a lei jurídica não é um imperativo (Ludwig 18, p. 96). Kersting, em primeiro lugar, afirma que a lei jurídica não é um imperativo hipotético, uma vez que não pressupõe, quanto à sua 
validade, nenhum fim (Kersting 15, p. 104); mas tampouco é um imperativo categórico, pois, em um tal imperativo, a lei prática se "estenderia até o momento do constrangimento [Nötigung], da necessitação [Necessitation] prática" (id., ibid., p. 105). Contudo, para Kersting, ainda que a lei jurídica não seja um imperativo, é "uma versão especializada do imperativo categórico, na fundamentação dos deveres aos quais corresponde uma faculdade de coerção" (id., ibid., p. 128). No mesmo sentido: "A lei jurídica universal, imperativo categórico no reino do direito, limita a liberdade de todos de acordo com o critério da compatibilidade mútua" (idem 16).

7. Pode-se ler na Vorlesung (Kant 11, p. 26): “Toda necessitação [Necessitation] moral é uma obrigação [Obligation], e a necessidade da ação a partir de regras da prudência, ou necessitação pragmática, não é obrigação. A obrigatoriedade [Verbindlichkeit] é pois prática, a saber, obrigatoriedade moral. Toda obrigatoriedade é ou por dever, ou uma obrigatoriedade por coerção".

8. A propósito da tradução de Beurteilung = Dijudicatio por appréciation, Guillermit escreve: "Não é, contudo, a idéia de preço evocado pela noção de apreciação que nos parece designá-la para traduzir o termo em Kant. É muito mais o sentido que ele toma quando falamos da apreciação de uma distância, por exemplo, pela razão precisa que a atividade de comparação que uma tal operação implica exige a adoção de um ponto de vista" (Guillermit 8)

9. Considerado livre significa: "todo ser que não pode agir de outro modo senão sob a idéia de liberdade é, por isso mesmo, realmente livre do ponto de vista prático" (Kant 10, IV, 448).

10. Em À Paz Perpétua, Kant chega a afirmar que "o problema do estabelecimento do Estado [unificação de uma multiplicidade de homens, segundo leis jurídicas], por mais duro que isso soe, é solucionável, mesmo para um povo de demônios (contanto que tenham entendimento)" (Kant 10, VIII, 366).

11. "De um lado, escreve Krüger, a lei obriga-me incondicionalmente e interdita todo campo livre à vontade; de outro, ela comanda uma maneira de proceder" (Krüger 17, p. 127)

12. Kant escreve em sua resenha do livro de Hufeland (Kant 10, VIII, 129): "Pois a questão aqui é apenas sob quais condições posso exercer coerção, sem contrariar os princípios universais do direito". Com relação ao direito penal, por exemplo, ainda que Kant tenha o jus taliones como a única idéia determinante a priori dele, isso não significa que o legislador possa desrespeitar a humanidade. Esse respeito ele deve tê-lo, não por razão éticas, mas de direito (id., ibid., VI, 362/363). Também a polêmica com Beccaria pode esclarecer em que medida a coerção é compatível com a autonomia. Resumindo, o argumento de Kant é o seguinte: "Ninguém sofre uma punição porque a quis, mas porque quis uma ação punível; pois não há pena quando ocorre a alguém o que ele quer, e é impossível ele querer uma pena(...) Quando, então, eu edito uma lei penal contra mim como criminoso, é a razão pura jurídico-legisladora (homo noumeno) em mim que me submete à lei 
penal como alguém capaz do crime, por consequência, como uma outra pessoa (homo phaenomeno) em meio a todos os demais em uma união civil" (Kant 10, VI, 335). Ora, assim como ninguém deseja ser punido, também não se deseja ser coagido. Pode-se, contudo, desejar a coerção, desde que se adote o ponto de vista da razão pura jurídico legisladora, ou seja: pode-se definir como ações passíveis de coerção aquelas que, de algum modo, possam a vir atentar contra o direito de cada um. É esse deslocamento entre essas duas perpectivas - fenomênica e noumênica - que garante a compatibilidade entre coerção e autonomia.

13. "Mesmo que se pudesse conceber uma legislação externa que conteria apenas leis positivas, ainda assim teria que lhe preceder uma lei natural fundando a autoridade do legislador (i.e., a faculdade de obrigar os outros através do seu simples arbítrio)" (Kant 10, VI, 224).

14. Uma formulação neste mesmo sentido encontra-se em À Paz Perpétua: "age de tal modo que possas querer que tua máxima deva tornar-se uma lei universal (qualquer que seja seu fim)" (Kant 10, VIII, 377).

15. Em uma carta aberta a Nicolai, Kant escreve, a propósito de uma constituição a ser escolhida pelo povo que, segundo o princípio do eudaimonismo (logo heteronômico), esse bem que pode vir a escolher uma constituição hereditária. Não, contudo, segundo o princípio eleuteronômico, a partir do que ele "considera a ele mesmo como legislador e, ao mesmo tempo, como submetido às leis". (Kant 10, VIII, 434).

16. Ludwig, Ralf. Kategorische Imperativ und Metaphysik der Sitten, Frankfurt, Peter Lang, 1992, p. 190 e também p. 211, onde se pode ler: "O que Kant introduz de novo na doutrina do direito é que ele emprega o imperativo categórico como condição da possibilidade da moralidade de uma ação coercitiva" (Ludwig 19).

17. Aqui se reformula uma passagem de Rohden, Valério, Interesse da razão e liberdade, São Paulo, Ática, 1981, p. 128: "Os conceitos podem expressar materialmente um determinado conteúdo, ou formalmente uma certa maneira ou regra de agir" (Rohden 20). 


\section{Referências Bibliográficas}

1. ALLISON, H. Kant's theory of freedom. Cambridge University Press, 1990.

2. ALMEIDA, G. "Moralidade e racionalidade na teoria moral kantiana". Em: Racionalidade e ação. Org. Valério Rohden. Porto Alegre, 1992.

3. BECK, L.W. A commentary of Kant's Critique of practical reason. Chicago University Press, 1960.

4. _L_Les deux concepts kantiennes du vuloir dans leur context politique". Em: La philosophie politique de Kant. Org. Eric Weil. Paris, PUF, 1962.

5. BOBBIO, N. Estado e direito no pensamento de Kant. Brasília, UnB, słd.

6. GOYARD-FABRE, S. Kant et le problème du droit. Paris, Vrin, 1975.

7. L La philosophie du droit de Kant. Paris, Vrin, 1996.

8. GUILLERMIT, L. L'elucidation critique du jugement de gôut selon Kant. Paris CNRS, 1982.

9. HÖFFE, O. "Kants kategorischer Imperativ als Kriterium des Sittlichen". Em: Ethik und Politik. Frankfurt am Main, Suhrkamp, 1979.

10. KANT, I. Kants Werke. Akademie Textausgabe. Berlin, Walter de Gruyter \& Co., 1968.

11._. Vorlesung über Ethik. Frankfurt am Main, Fischer, 1990.

12. _. "Primeira introdução à Crítica do Juízo". Em: Duas introduções à Crítica do Juízo”. Trad. Rubens Rodrigues Torres Filho. São Paulo, Iluminuras, 1995.

13. KAULBACH, F. Immanuel Kants Grundlegung zur Metaphysik der Sitten. Darmstadt, Wissenschaftliche Buchgesellschaft, 1982.

14. Studien zur späten rechtsphilosophie Kants. Königshausen und Neumann, Würzburg, 1982. 
15. KERSTING, W. Wohlgeordnet Freiheit. Frankfurt am Main, Suhrkamp, 1993.

16. _Politics, freedom and order: Kant's political philosophy". Em: Kant. Org. Paul Guyer, Cambridge University Press, 1992.

17. KRÜGER, G. Critique et morale chez Kant. Paris, Beauchesne, 1962.

18. LUDWIG, B. Kants Rechtslehre. Hamburg, Felix Meiner, 1987.

19. LUDWIG, R. Kategorischer Imperativ und Metaphysik der Sitten: die Frage nach der Einheitlichkeit von Kants Ethik. Frankfurt am Main, Peter Lang, 1992.

20. ROHDEN, V. Interesse da razão e liberdade. São Paulo, Ática, 1981.

21. ROUSSEAU, J. J. Obras escolhidas. São Paulo, Abril, 1983.

22. ROUSSET, B. La doctrine kantienne de l'objectivité. Paris, Vrin, 1967.

23. TERRA, R. R. A política tensa. São Paulo, Iluminuras, 1995.

24. WEIL, E. Problèmes kantiennes. Paris, Vrin, 1970. 